\title{
BRINGING CONCEPTS TOGETHER: INTERDISCIPLINARITY, TRANSDISCIPLINARITY, AND SSH INTEGRATION
}

\author{
JOËL GRAF \\ DOI: 10.22163/fteval.2019.364
}

\section{ABSTRACT}

$\mathrm{T}$ he European Commission has made a strong commitment to integrate the Social Sciences and Humanities (SSH) across Horizon 2020. The aim is to enhance the impact of activities tackling societal challenges. However, the question on how such an "SSH integration" should happen in practice still offers room for discussion. Therefore, this article focuses on the methodological challenges of bringing SSH into collaborative Horizon 2020 projects. It emphasises that $\mathrm{SSH}$ integration is a special case of inter- and transdisciplinarity, since different scientific disciplines as well as non-academic stakeholders are involved in the research process. Taking inter- and transdisciplinary expertise more systematically into account may thus contribute to both better proposals and improved project implementation for Horizon 2020 and the upcoming "Framework Programme Horizon Europe".

\section{INTRODUCTION}

The idea of SSH integration in Horizon 2020 goes back to the decision of the European Parliament and the Council stating that "social sciences and humanities will be mainstreamed as an essential element of the activities needed to tackle each of the societal challenges to enhance their impact."1 This statement sounds convincing and seems intuitively plausible. However, the past years have shown that such an "SSH integration" is far from trivial and requires sound methodological tools. The question of "how" to integrate SSH disciplines into consortia has not been in the focus of the European Commission (EC) so far and remains mainly up to the commitment and competence of the individual applicant. ${ }^{2}$ Neither has there been a broad reflection on how SSH integration relates to other concepts such as inter- and transdisciplinarity. ${ }^{3}$ Against this background, the present article highlights the potential of using theoretical and methodological expertise in the fields of inter- and transdisciplinarity in order to improve the impact generating processes in SSH research.

\section{INTERDISCIPLINARITY, TRANSDISCIPLINARITY AND SSH INTEGRATION}

When looking into Horizon 2020 topics one finds references to a broad range of collaborative research approaches, such as SSH integration, transdisciplinarity, interdisciplinarity, multidisciplinarity, crossdisciplinarity, multisectorality, co-creation and co-design. ${ }^{4}$ For a common ground of discussion, it is crucial to define those terms and clarify the relationships between each other's. In what follows, this will be done with interdisciplinarity, transdisciplinarity and SSH integration.

The FAO section of the participant portal defines interdisciplinarity as "the integration of information, data, techniques, tools, perspectives,

European Parliament and Council (2013). Regulation (EU) No 1291/2013 of 11 December 2013 establishing Horizon 2020, Annex I, 121 (URL: https://eur-lex. europa.eu/LexUriServ/LexUriServ.do?uri=0J:L:2013:347:0104:0173:EN:PDF, last access 31.10.2018).

2 The dedicated monitoring reports of the European Commission are limiting their assessment on how many SSH partners consortia involve and how much budget is dedicated to SSH researchers. These figures are of high relevance. However, it would be also important to assess the question on how SSH integration happened (common problem framing, workshops etc.). This would require a qualitative rather than a quantitative approach. B. I. Birnbaum et al. (Ed.). (2017). 2nd Monitoring report on SSH-flagged projects. Luxembourg: Publication Office of the European Union (URL: https://publications.europa.eu/ en/publication-detail/-/publication/acac40f5-e84b-11e6-ad7c-01aa75ed71a1, last access 31.10.2018).

3 It is significant that a 2018 topic in the Societal Challenge 6 asks for "lessons from the practices of interdisciplinarity" but explicitly excludes discussions on the "epistemology of interdisciplinarity".

European Commission 2018). Work Programme 2018-2020: Europe in a changing world - Inclusive, innovative and reflective societies, topic GOVERNANCE-15-2018: Taking lessons from the practices of interdisciplinarity in Europe, 54-55 (version of 24.07.2018. URL: http://ec.europa.eu/research/participants/data/ref/h2020/wp/2018-2020/main/h2020-wp1820-societies_en.pdf, last access 31.10.2018).

4 An example for the broad mix of concepts is to be found in the introduction of the Societal Challenge 5 Work Programme. It asks for: "a challenge-driven solutions-oriented, trans-disciplinary perspective that integrates technology, business models and economic organisation, finance, governance and regulation as well as skills and social innovation, and involves co-creation of knowledge and co-delivery of outcomes with economic, industrial and research actors, public authorities and/or civil society." (My italics, JG). European Commission (2018). Work Programme 2018-2020: Climate action, environment, resource efficiency and raw material, introduction, 6 (version of 24.07.2018. URL: http://ec.europa.eu/research/participants/data/ref/h2020/wp/2018-2020/main/ h2020-wp1820-climate_en.pdf, last access 31.10.2018). 
concepts or theories from two or more disciplines. Disciplines may be from the natural sciences, technology, engineering, economics, social sciences and humanities. "5 This definition focuses on the integration of knowledge from different academic disciplines. ${ }^{6}$

Even though explicit references to transdisciplinarity are to be found in various Horizon 2020 topic texts, it is quite difficult to find an official definition by the EC. A guidance document for evaluators published in 2014 states that "trans-disciplinarity [...] refers to approaches and methodologies that integrate as necessary (a) theories, concepts, knowledge, data, and techniques from two or more scientific disciplines, and (b) nonacademic and non-formalized knowledge. In this way, trans-disciplinarity contributes to advancing fundamental understanding or solving complex problems while fostering multi-actor engagement in the research and innovation process." "This definition goes beyond the collaboration between scientific disciplines by including the knowledge of non-academic stakeholders. ${ }^{8}$

The process of SSH integration is explained on the participant portal as follows: "Social Sciences and Humanities (SSH) are needed to tackle many of the complex societal challenges addressed in H2O2O, and contributions from one or more of these disciplines are frequently necessary for a successful proposal. These contributions are usually part of an interdisciplinary approach, involving either:

- collaboration between SSH disciplines and/or,

- collaboration between SSH disciplines and non-SSH disciplines such as natural sciences, medicine and technology. ${ }^{\text {"g }}$

SSH integration can therefore be considered as a specific form of interdisciplinarity. ${ }^{10}$ At the same time, SSH flagged topics are often requiring the involvement of non-academic stakeholders. In practice, integrating SSH researchers thus also touches issues of transdisciplinarity.

\section{STATE OF THE ART AND INVOLVEMENT OF EXPERTS}

SSH integration can only contribute to excellent science if the integration process itself is meeting state of the art principles. Therefore, existing expertise on inter- and transdisciplinary methodologies should to be taken into account by all stakeholders, i.e. the EC, applicants, "National Contact Points" (NCPs), and evaluators.

Such expertise is to be found at many different levels. Switzerland may serve as an example. The Swiss Academies of Arts and Sciences are hosting td-net, a dedicated contact point for researchers and funders in the field of inter- and transdisciplinary research and teaching. ${ }^{11}$ Amongst others, td-net provides a platform with concrete tools for the implementation of inter- and transdisciplinarity. Another institution dedicated to collaborative research is the Department of Environmental Systems Science at the ETH Zurich, which includes the transdisciplinary laboratory TdLab. TdLab aims at "integrating knowledge and values from different scientific perspectives, as well as from other societal actors". ${ }^{12}$

Europe has a lot of experts on inter- and transdisciplinarity. ${ }^{13}$ Bringing them together with Horizon 2020 applicants could lead to improved proposals and better project implementation.

$4 \quad$ An example for the broad mix of concepts is to be found in the introduction of the Societal Challenge 5 Work Programme. It asks for: "a challenge-driven, solutions-oriented, trans-disciplinary perspective that integrates technology, business models and economic organisation, finance, governance and regulation as well as skills and social innovation, and involves co-creation of knowledge and co-delivery of outcomes with economic, industrial and research actors, public authorities and/or civil society." (My italics, JG). European Commission (2018). Work Programme 2018-2020: Climate action, environment, resource efficiency and raw material, introduction, 6 (version of 24.07.2018. URL: http://ec.europa.eu/research/participants/data/ref/h2020/wp/2018-2020/main/ h2020-wp1820-climate_en.pdf, last access 31.10.2018).

$5 \quad$ "How should interdisciplinarity and stakeholder knowledge be addressed and evaluated in Horizon 2020 proposals?". European Commission (2016). FA0 Participant Portal, ID 935 (09-02-2016) (URL: https://ec.europa.eu/research/participants/portal/desktop/en/support/faqs/faq-935.html, last access 31.10.2018).

$6 \quad$ Such an understanding of interdisciplinarity corresponds with the state of the art of the relevant research literature. G. Hirsch Hadorn et al. (2008): The Emergence of Transdisciplinarity as a Form of Research. In G. Hirsch Hadorn et al. (Ed), Handbook of Transdisciplinary Research (Dordrecht: Springer), 19-39, here 28.

$7 \quad$ European Commission (2014). "How should trans-disciplinarity be addressed and evaluated in proposals?". Guidance for evaluators of Horizon 2020 proposals: 6 (version 1.0, 15.07.2014, URL: http://ec.europa.eu/research/participants/data/ref/h2020/grants_manual/pse/h2020-evaluation-faq_en.pdf, last access 31.10.2018)

$8 \quad$ This is in line with the state of the art of the dedicated research community. G. Hirsch Hadorn et al. (2008): The Emergence of Transdisciplinarity as a Form of Research. In G. Hirsch Hadorn et al. (Ed), Handbook of Transdisciplinary Research (Dordrecht: Springer), 19-39, here 29.

$9 \quad$ European Commission (2018). "How should Social Sciences and Humanities (SSH) be addressed and evaluated in H2020 proposals?". FA0 Participant Portal, ID 938 (26.01.2018) (URL: https://ec.europa.eu/research/participants/portal/desktop/en/support/faqs/faq-938.html, last access 26.01.2018).

10 See also C. Schmaltz (2016). Multi- and Transdisciplinary Research in Horizon 2020. Presentation given at the National Network and Information Event 2016, NCP Life Sciences, Cologne, 01 June 2016, here 7. (URL: https://www.healthncp.net/sites/default/files/downloads/Plenar01_Health.pdf, last access 31.10.2018). Also note that transdisciplinarity is here defined as "creating a unity of intellectual frameworks beyond the disciplinary perspectives" (6). This understanding of the concept differs from the one referred to above (Guidance for evaluators" (2014)).

11 td-net: Network for Transdisciplinary Research (URL: http://www.transdisciplinarity.ch, last access 31.10.2018)

12 USYS TdLab (URL: http://www.tdlab.usys.ethz.ch, last access 31.10.2018).

13 See also the Horizon 2020 project ACCOMPLISSH (URL: https://www.accomplissh.eu, last access 04.12.2018). 


\section{EURESEARCH PILOT EVENT ON TRANSDISCIPLINARITY IN HORIZON 2020}

In April 2018, Euresearch, the Swiss advisory network on "European Research and Innovation", organised an event on transdisciplinarity in Horizon 2020.14 Applicants, coordinators, evaluators and experts discussed on how theoretical and methodological expertise in transdisciplinarity may contribute to both better proposals and improved implementation of projects.

Experts on transdisciplinary methodologies assessed the general design of collaborative projects in Horizon 2020. They especially mentioned the importance of the common problem framing by the consortium members. ${ }^{15}$ Against this backdrop, one of the main challenges concerns the implementation of transdisciplinary processes within top-down calls, as the latter are often strongly pre-defining the scope of the projects.

In a second step, evaluators and coordinators of Horizon 2020 discussed the concrete potential of transdisciplinarity within proposals and project implementation. It became obvious that in certain research fields (such as "Public Health and Sustainable Development") the use of transdisciplinary tools is daily business. In other fields, transdisciplinarity happens rather implicitly and by learning by doing. As for the evaluation, all panellists agreed on that an explicit consideration of transdisciplinarity would make proposals more credible. However, the involvement of transdisciplinary experts could also lead to conflict of aims as such experts generate additional costs for the consortium. The goal would therefore be to convince evaluators that the incorporation of transdisciplinary experts in consortia is an integral part of collaborative research and innovation.

\section{HORIZON EUROPE AND MISSION-ORIENTED RESEARCH}

In June 2018, the EC published its proposal on the "9th European Framework Programme Horizon Europe". One of the main recommendations is the preservation of the three pillar approach of Horizon 2020. For the present article, the pillar "Global Challenges and Industrial Competitiveness" is of special interest. It should "encourage cross-disciplinary, cross-sectoral, cross-policy and cross-border collaboration in pursuit of the UN SDGs and the competitiveness of the Union's industries therein." ${ }^{16} 0 \mathrm{n}$ top of the regular call for proposals "a limited set of highly visible missions will be introduced. [...] Missions, with ambitious but time-bound and achievable goals, should speak to the public and engage it where relevant. They will be co-designed with Member States, the European Parliament, stakeholders and citizens. ${ }^{17}$ On this basis, it seems very likely that SSH integration, as well as inter- and transdisciplinarity, will play an important role in the upcoming "Framework Programme".

However, there remain some open questions which have to be considered. The role of SSH is not explicitly addressed in the document. The most important programme for SSH Integration in Horizon 2020 was the "Societal Challenge" 6 on "Inclusive Societies". While there will be a similar cluster in Horizon Europe, the budget will be comparatively low. ${ }^{18} \mathrm{t}$ remains to be seen how much budget from the other clusters will be dedicated to SSH research. As for the question of inter- and transdisciplinarity, the idea of co-designing the newly introduced missions together with citizens is certainly a laudable initiative. There is, though, an obvious area of tension between the top-down approach of highly prescriptive topic texts and/or missions on the one hand and inter- and transdisciplinary processes on the other hand, as the latter require certain openness. ${ }^{19}$

\section{CONCLUSION AND RECOMMENDATIONS}

From a methodological point of view, SSH integration is a special case of interdisciplinarity. As SSH flagged topics often involve nonacademic stakeholders, transdisciplinarity is also of high relevance. The relation between SSH integration, interdisciplinarity and transdisciplinarity should therefore be thoroughly discussed and the results should be made available for the Horizon 2020 stakeholders.

The EC should reconsider the methodological terminology for collaborative projects, especially regarding the topic texts. One possibility would be to include basic concepts in the glossary of the "Funding and Tenders Portal". Some definitions are already provided on the Horizon 2020 FA0 section. They are, however, somewhat hidden and incomplete (e.g. no reference to transdisciplinarity is given). As for the "9th European Framework Programme Horizon Europe", the EC should include experts on inter- and transdisciplinarity. The latter could give valuable inputs on

14 Euresearch event on "Transdisciplinarity in Horizon 2020. Challenges and Approaches". Bern, 24 April 2018 (URL: https://www.euresearch.ch/en/events/ event-detail/showUid/746/, last access 31.10.2018)

15 C. Pohl et al. (2017). Ten Reflective Steps for Rendering Research Societally Relevant. GAIA 26/1 (2017), 43-51.

16 European Commission (2018). Proposal for a Regulation of the European Parliament and of the Council Establishing Horizon Europe (COM(2018) 435 final, 2018/0224 (COD)), 17 (URL: https://ec.europa.eu/commission/sites/beta-political/files/budget-may2018-horizon-europe-regulation_en.pdf, last access 31.10.2018).

17 European Commission (2018). Proposal for a Regulation of the European Parliament and of the Council Establishing Horizon Europe (COM(2018) 435 final, 2018/0224 (COD)), 10 (URL: https://ec.europa.eu/commission/sites/beta-political/files/budget-may2018-horizon-europe-regulation_en.pdf, last access 31.10.2018).

18 The proposal suggests around 3 billion Euro for a cluster called Inclusive and Secure Societies. European Commission (2018). Proposal for a Regulation of the European Parliament and of the Council Establishing Horizon Europe (COM(2018) 435 final, 2018/0224 (COD)), 32 (URL: https://ec.europa.eu/commission/ sites/beta-political/files/budget-may2018-horizon-europe-regulation_en.pdf, last access 31.10.2018).

19 C. Pohl et al. (2017). Ten Reflective Steps for Rendering Research Societally Relevant. GAIA 26/1 (2017), 43-51; L. van Drooge and J. Spaapen (2017). Evaluation and Monitoring of Transdisciplinary Collaborations. The Journal of Technology Transfer (2017) (URL: https://doi.org/10.1007/s10961-017-9607-7, last access 31.10.2018). 
do's and don'ts regarding the framing of collaborative projects (e.g. regarding the top-down approach, common problem framing, co-design etc.).

Collaborative Horizon 2020 projects often involve different academic disciplines and non-academic stakeholders. In these cases, applicants should explicitly address methodological issues regarding the integration of knowledge and the elaboration of common research and innovation results. They should take into account the state of the art research on corresponding concepts and - if necessary - involve experts on interand transdisciplinarity both for the proposal writing and the project implementation

Evaluators should be thoroughly briefed about SSH integration, not only regarding the numerical involvement of SSH researchers but also regarding the actual process of how the specific competences are integrated into the consortium. In general, evaluators should be systematically looking at inter- and transdisciplinary methodologies.

"National Contact Points" dealing with SSH integration should advise applicants about the basic challenges of integrating the knowledge of different stakeholders within collaborative projects. Dedicated tools such as webinars, factsheets etc. - do already exist in some cases ${ }^{20}$ and should further be developed, also by the NCP networks. Specific events as the one described above may also contribute to the discussion.

\section{REFERENCES}

Birnbaum, B. I. et al. (Ed.). (2017). 2nd Monitoring report on SSHflagged projects. Luxembourg: Publication Office of the European Union (URL: https://publications.europa.eu/en/publication-detail/-/publication/acac40f5-e84b-11e6-ad7c-01aa75ed71a1, last access 31.10.2018).

European Commission (2018). Horizon 2020 Work Programme 20182020: Climate action, environment, resource efficiency and raw material, introduction (version of 24.07.2018. URL: http://ec.europa.eu/research/ participants/data/ref/h2020/wp/2018-2020/main/h2020-wp1820-climate_en.pdf, last access 31.10.2018).

European Commission (2018). Horizon 2020 Work Programme 20182020: Europe in a changing world - Inclusive, innovative and reflective societies (version of 24.07.2018. URL: http://ec.europa.eu/research/ participants/data/ref/h2020/wp/2018-2020/main/h2020-wp1820-societies_en.pdf, last access 31.10.2018).

European Commission (2016). "How should interdisciplinarity and stakeholder knowledge be addressed and evaluated in Horizon 2020 proposals?". FAO Participant Portal, ID 935 (09-02-2016) (URL: https:// ec.europa.eu/research/participants/portal/desktop/en/support/faqs/ faq-935.html, last access 31.10.2018).

European Commission (2018). "How should Social Sciences and Humanities (SSH) be addressed and evaluated in H2020 proposals?". FAO Participant Portal, ID 938 (26.01.2018) (URL: https://ec.europa.eu/research/ participants/portal/desktop/en/support/faqs/faq-938.html, last access
26.01.2018).

European Commission (2014). "How should trans-disciplinarity be addressed and evaluated in proposals?" In Guidance for evaluators of Horizon 2020 proposals: 6 (version 1.0, 15.07.2014, URL: http://ec.europa. eu/research/participants/data/ref/h2020/grants_manual/pse/h2020evaluation-faq_en.pdf, last access 31.10.2018).

European Commission (2018). Proposal for a Regulation of the European Parliament and of the Council Establishing Horizon Europe (COM(2018) 435 final, 2018/0224 (COD)) (URL: https://ec.europa.eu/commission/ sites/beta-political/files/budget-may2018-horizon-europe-regulation_ en.pdf, last access 31.10.2018).

European Parliament and Council (2013). Regulation (EU) No 1291/2013 of 11 December 2013 establishing Horizon 2020, Annex I (URL: https:// eur-lex.europa.eu/LexUriServ/LexUriServ.do?uri=0J:L:2013:347:0104:01 73:EN:PDF, last access 31.10.2018).

Hirsch Hadorn, G. et al. (2008). The Emergence of Transdisciplinarity as a Form of Research. In G. Hirsch Hadorn et al. (Ed), Handbook of Transdisciplinary Research (Dordrecht: Springer), 19-39.

Net4Society4 (n.d.). Factsheet on "Keys to successful integration of Social Sciences and Humanities in Horizon 2020" (URL: https://www. net4society.eu/_media/170110_Factsheet_Expert\%20meeting_INTEGRATION_def.pdf, last access 31.10.2018).

Pohl, C. et al. (2017). Ten Reflective Steps for Rendering Research Societally Relevant. GAIA 26/1 (2017), 43-51.

Schmaltz, C. (2016). Multi- and Transdisciplinary Research in Horizon 2020. Presentation given at the National Network and Information Event 2016, NCP Life Sciences, Cologne, 01 June 2016

van Drooge, L. and Spaapen, J. (2017). Evaluation and Monitoring of Transdisciplinary Collaborations. The Journal of Technology Transfer (2017) (URL: https://doi.org/10.1007/s10961-017-9607-7, last access 31.10.2018).

\section{AUTHOR}

\section{JOËL GRAF}

Euresearch

Effingerstrasse 19, Bern, 3008 (Switzerland)

E: joel.graf@euresearch.ch

\section{KEYWORDS:}

Interdisciplinarity, Transdisciplinarity, SSH Integration

20 See, for instance Net4Society4 (n.d.). Factsheet on "Keys to successful integration of Social Sciences and Humanities in Horizon 2020" (URL: https://www. net4society.eu/_media/170110_Factsheet_Expert\%20meeting_INTEGRATION_def.pdf, last access 31.10.2018). 